\title{
TRAFFIC ACCIDENTS CAUSED BY PEDESTRIANS IN TURKEY
}

\author{
Emre Kuşkapan ${ }^{1}$, Kadir Diler Alemdar ${ }^{2}$, Ömer Kaya ${ }^{3}$, Muhammed Yasin Çodur ${ }^{4}$ \\ 1,2,3,4 Erzurum Technical University, Civil Engineering, Transportation Department, 25050, Erzurum, Turkey
}

Received 15 June 2018; accepted 15 January 2019

\begin{abstract}
Traffic accidents in the world cause various losses in economic and social aspects. Although the recovery of economic losses can be made easily and in a short time, it is not possible to recovery for social losses. Despite precautionary measures, it is seen that the loss of lives in traffic accidents does not decrease to the desired level. When the accidents are examined, it is seen that a large part is human caused. The first order is traffic accidents caused by driver mistakes. However, the amount of accident caused by the pedestrian is too much. Having a variety of sanctions for drivers can be a deterrent, but for pedestrian defects, this situation is neglected and it seems that the necessary sanctions are few. In this study; it has been examined pedestrian defects occurring in traffic accidents in Turkey. Various evaluations were made by using statistical data and solution proposal for pedestrian-vehicle traffic accidents.
\end{abstract}

Keywords: traffic accidents, pedestrians defect, traffic education, Turkey.

\section{Introduction}

With the developing technology, the number of vehicles is increasing day by day. Increasing number of vehicles, it causes the traffic congestion and frequently traffic accidents. Despite the precautions have been taken, this increase in traffic accidents causes both material and spiritual loss. When the deaths in the world are examined, 2.1 percent is caused by traffic accidents. Traffic accidents, where 1 million 200 thousand people have lost their lives every year, ranks 11 th among causes of death. When traffic accidents are examined, the causative factors are divided into human factors and external factors. Human factors are; driver, pedestrian and passenger. External factors are; vehicle and road. The biggest factor in traffic accidents is people. Among the human factors, the driver-induced traffic accidents are the most common. The second factor in traffic accidents following drivers is the pedestrian. The rates of these defects vary from country to country. Considering the pedestrian traffic accidents in Turkey, pedestrian traffic accidents are more likely to occur. There are various sanctions for the drivers in order to reduce traffic accidents and many of them are applied. However, although there are some sanctions in the laws of traffic accidents caused by pedestrians, there are not many enforcements.

Aziz et al., (2017) Pedestrian-vehicle accidents talked about the fact that the high mortality rate is a big problem in New York. Has developed a random parameter logit model to explain the severity ratings of pedestrian injuries he has done. Zębala et al., (2012) purpose of the article is to present the results of the research conducted at the Forensic Research Center in Kraków. Depending on the age, sex and movement

${ }^{4}$ Corresponding author: mycodur@erzurum.edu.tr 
of pedestrians in a specially designated experimental area, average pedestrian speeds have been determined. Kadali and Vedagiri (2013) examined pedestrian behavior in complex traffic conditions. In particular, this study analyzes in detail the behavior of pedestrians according to their age and physical condition. Ozen et al., (2014) purpose of the study, determine the thoughts of individuals about the causes of traffic accidents and to measure the general perception levels of traffic in Usak. Economic situation of traffic accidents, rather than social situation, has been assessed. The causes of the traffic accidents were evaluated by pedestrian and driver's point of view and the level of awareness of the traffic on the subjects were examined.

On the other hand, other important findings of this study are that the education provided in the driver's courses is inadequate and the measures taken to prevent traffic accidents are not sufficient and successful. Findings of this study reveal the results that can be included among the decision making mechanisms of authorities working on traffic. A number of studies identified that there exists strong relationship between education factors of pedestrians and crash risk (Gokdag and Atalay, 2015). For example, effective traffic education, it will be possible to get the best result, and traffic education will be effective on the decrease in accidents. For this purpose, with the fact that preschool education is very important, traffic education should be given to children within the scope of formal education, supported by systematic and scientific techniques, as well as education of the individual in the family environment.

Haleem et al., (2015) study identifies and compares the significant factors affecting pedestrian crash injury severity at signalized and unsignalized intersections. This paper used that identifies significant factors affecting pedestrian injury severity at signalized and unsignalized intersections using three years of pedestrian crash data (2008-2010) from Florida.

Glász and Juhász (2017) studied that carpedestrian and car-bicycle accidents in Hungary. Between 2011 and 2014, accident data were used for car bike accidents. The aim of this work is to develop a sensor system that can be integrated into cars. With this sensor it is possible to interpret the main causes and situations that led to car-pedestrian and car-bicycle accidents in Hungary. As a result of the examinations; it was seen that the pedestrians caused accidents due to road trips without paying attention to the road priority, and the vehicles caused accidents due to the speed infringement. It has been interpreted that people should be taught better the rules. According to Levulyte et al., (2017) traffic accident is required detailed analysis. In this study, examined of the pedestrian-vehicle collision case was determined and the role of the pedestrians for the accident it was investigated. It is a comprehensive approach for education and enforcement with the focus on both driver and pedestrian. As a result of the study, it was designed a systems have been devised to warn drivers to increase traffic safety. This sensor is used with aim to alert drivers about pedestrian approach. It was also mentioned that the injury of the accidents would be reduced due to the fact that the main body of the vehicle consists of smarter materials.

Codur and Tortum (2015) examined an artificial neural network model for the prediction of highway accidents. Injuries and deaths are not only the result of traffic 
accidents, but also lead to the waste of social wealth. It is very important to reduce the highway traffic accidents in the developing countries like Turkey, and therefore the traffic safety should be improved by the analysis of accident characteristics. Uttley and Fotios (2017) argued that it increased the possibility of crashing pedestrians in the dark. The purpose of the pedestrian crossings is to make the transition safer. He mentioned that there is a need for light to make transitions more secure. Xie et al., (2017) study pedestrian crossings analysis with a survey was conducted in 7 different regions in Hong Kong city. The decision to pass the pedestrian, the gender of the humans and the speed of walking, vehicle flow and pedestrian crossing have been found to affect the situation. Human factor in traffic accidents has caused many studies in this very serious issue. When studies are examined, there are many studies about traffic accidents caused by drivers. However, there are not enough studies about pedestrian traffic accidents. For this purpose, caused by pedestrians traffic accidents in Turkey is examined in the study was made some comments using numerical data.

\section{Materials and Methods}

In this study, investigated traffic accidents where there are fatalities and injuries in Turkey (2016). Factors affecting the accidents were evaluated, especially were examined traffic accidents caused by pedestrian. The data used in this study, the General Directorate of Highways (GDH), Turkish Statistical Institute (TSI) and Turkey National Police (TNP) is taken

from these institutions. Data for the study in 2016 in a traffic accident that occurred in Turkey were used. The number of cars are 142 per thousand people in Turkey. This number is about 491 in member countries of the European Union. A number of deaths in traffic accidents per million people while 91 in Turkey, the number of member countries of the European Union 51 (Table 1).

Table 1

Traffic Accidents in 2016

\begin{tabular}{|c|c|c|}
\hline & $\begin{array}{c}\text { Number of cars per } \\
\text { thousand people }\end{array}$ & $\begin{array}{c}\text { Number of deaths in traffic } \\
\text { accidents per million people }\end{array}$ \\
\hline Turkey & 142 & 91 \\
\hline Member of the European Union & 491 & 51 \\
\hline
\end{tabular}

Source: (General Directorate of Highways, 2016a)

This shows the rates, the number of cars per capita in Turkey, although less according to the member states of the European Union, the rate of people who died in traffic accidents in Turkey is higher than the member states of the European Union.

Many reasons may be more of the traffic accident and death rates occurring in Turkey.
Therefore, it is necessary to examine the factors that are effective in traffic accidents. The main factors that cause traffic accidents can be examined in 4 groups: humans, road, vehicle and environmental conditions.

The fact that the four basic elements differ in their share of the accidents, leads to the need to determine the classification of accidents. 


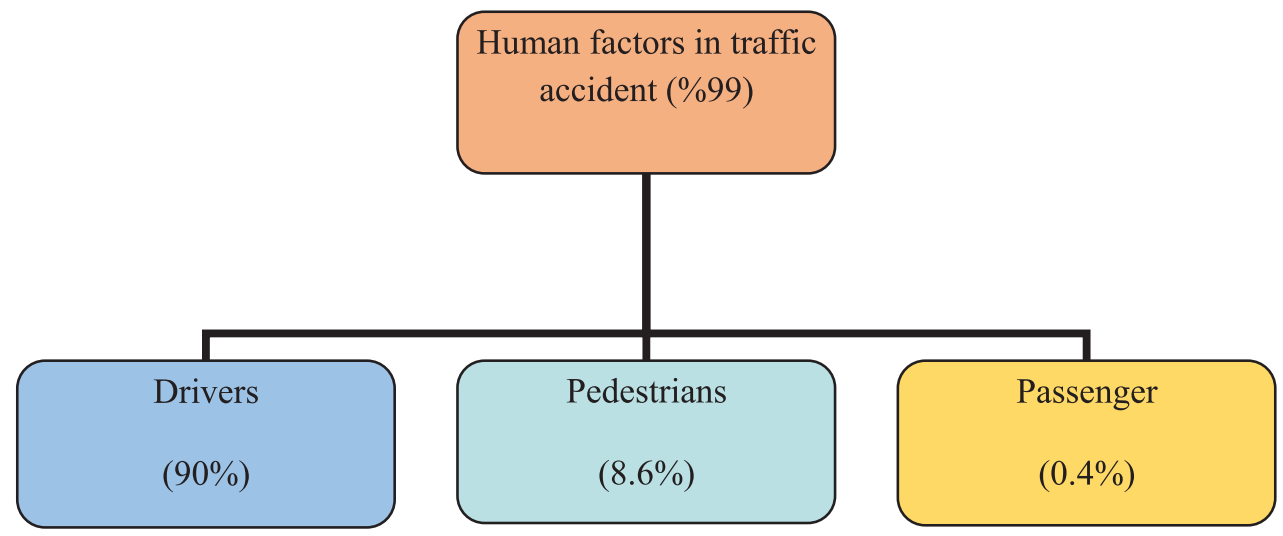

Fig. 1.

Human Factors in Traffic Accidents Average in 2016

Source: (Turkish Statistical Institute, 2018)

Human factors are $99 \%$ and the total of other factors is only $\% 1$ in traffic accidents in Turkey (Figure 1). The human factor is examined in three categories: driver (90\%), pedestrians $(8.6 \%)$, and passenger $(0.4 \%)$.

If we need to investigate traffic accidents in another way; traffic accidents are divided into two according to where they are: urban areas and rural areas. When the accidents were examined Table 2 , it was determined that the number of deaths in rural areas was much higher, even though the number of accidents was higher in urban areas. It has been found that the accidents in urban areas are more materially damaged. The most effective factor is that the speed of the vehicle is lower in urban areas than in rural areas.

Table 2

Traffic Accident Statistics in 2016

\begin{tabular}{|c|c|c|c|}
\hline Traffic Accidents & Urban Areas & Rural Areas & Total \\
\hline $\begin{array}{c}\text { Total Accident Distribution } \\
\text { (injured or death) }\end{array}$ & 138,716 & 46,412 & 185,128 \\
\hline Killed in Traffic Accidents & 3,255 & 3,092 & 6,347 \\
\hline Injured in Traffic Accident & 13,461 & 43,320 & 178,781 \\
\hline Killed & 3,527 & 3,773 & 7,300 \\
\hline Injured & 204,459 & 99,353 & 303,812 \\
\hline
\end{tabular}

Source: (Turkey National Police, 2018a)

As it is seen in the Table 2, the number of traffic accidents is higher in urban areas. But mortality rate in urban areas is lower than in rural areas. On the other hand, the amount of injury in urban areas is more than in rural areas. This means that although the number of accidents in urban areas is much, the severity of the accident is low. Accidents occurring in these four groups were evaluated as sub-headings. 
Table 3

Killed-Injured Traffic Accidents by According to the Report in 2016

\begin{tabular}{|c|c|c|}
\hline Type of Accident & Urban Areas & Rural Areas \\
\hline Head-on collision & $6.48 \%$ & $6 \%$ \\
\hline Rear-end collisions & $10.22 \%$ & $11.94 \%$ \\
\hline Sideswipe collisions & $34.83 \%$ & $13.74 \%$ \\
\hline Collide side by side & $1.44 \%$ & $0.96 \%$ \\
\hline Collision standing car & $2.27 \%$ & $1.12 \%$ \\
\hline Pileup & $0.16 \%$ & $0.25 \%$ \\
\hline Multiple collision & $0.14 \%$ & $0.16 \%$ \\
\hline Collision with obstacle/ object & $6.04 \%$ & $7.03 \%$ \\
\hline Pedestrian collision & $22.63 \%$ & $2.86 \%$ \\
\hline Animal collision & $0.27 \%$ & $0.95 \%$ \\
\hline Overturn $\backslash$ Skid $\backslash$ Tumble & $8.06 \%$ & $16.33 \%$ \\
\hline Off the road & $6.63 \%$ & 38.15 \\
\hline Human fall from vehicle & $0.79 \%$ & $0.42 \%$ \\
\hline Object fall from vehicle & $0.04 \%$ & $0.08 \%$ \\
\hline$($ Turke $\%$ tion $\%$ & \\
\hline
\end{tabular}

Source: (Turkey National Police,2018b)

When Table 3 is examined in detail, the flaws and carelessness of the drivers seem to have come to the forefront. It is seen that the amount of driver-induced traffic accidents and pedestrian impacts is very much. This situation brings to mind the question: What are the pedestrian defects in traffic accidents that occur between the pedestrian and the vehicle? If we want to be able to answer this question, we need to know precisely what pedestrian defects we can come up with.

\section{Results and Discussion}

Traffic accidents caused by pedestrians in Turkey of around $8.6 \%$ (Figure 1). This rate has been declining in recent years. The reduced number of pedestrian-driven traffic accidents, despite the fact that the number of traffic accidents is not reduced, may lead to the comment that the bows have begun to comply more with the rules. Thanks to the high level of education in urban areas leads to the idea of lower traffic accidents caused by pedestrians. However, when the defect rates are examined, the rate of traffic accidents caused by pedestrians in urban areas is about $11 \%$, while the rate of traffic accidents caused by pedestrians in rural areas is about $1.5 \%$. There can be a variety of reasons why the difference is too many. For example; it can be said that the roads in the urban regions are close to the houses and the intersections which are intersection points of the vehicles and the pedestrians in these regions are many. Therefore, it is necessary to examine in detail traffic accidents caused by pedestrians. Pedestrian defects are classified in the following Table 4 depending on two factors, urban and rural, depending on these reasons:

- Failure to comply with passing rules in places where crossings and junctions are not available; 
- To reduce the risk of traffic on the road of vehicles;

- Failure to obey traffic lights and signs;

- Failure to comply with traffic rules in transit;

- $\quad$ Entering the vehicle way;

- Not taking precautions for the nights;

- Not leave the left side of the road;
- Not to take necessary precautions in the accident area;

- Failure to comply with other rules concerning traffic safety;

- Throwing something out of the way to make the traffic harder;

- To go to an alcoholic route.

Table 4

Information on Passenger Damages Affecting Death and Injured Traffic Casualties in 2016

\begin{tabular}{|c|c|c|c|c|c|c|}
\hline \multirow{2}{*}{$\begin{array}{c}\text { Traffic accidents } \\
\text { in 2016 }\end{array}$} & \multicolumn{2}{|c|}{ Urban areas } & \multicolumn{2}{c|}{ Rural areas } & \multicolumn{2}{c|}{ Total } \\
\cline { 2 - 7 } & $\begin{array}{c}\text { Number of } \\
\text { defects }\end{array}$ & $\%$ & $\begin{array}{c}\text { Number of } \\
\text { defects }\end{array}$ & $\%$ & $\begin{array}{c}\text { Number of } \\
\text { defects }\end{array}$ & $\%$ \\
\hline a & 8,226 & 46.06 & 290 & 36.16 & 8,516 & 45.63 \\
\hline $\mathbf{b}$ & 2,833 & 15.86 & 110 & 13.72 & 2,943 & 15.77 \\
\hline $\mathbf{c}$ & 2,245 & 12.57 & 30 & 3.74 & 2,275 & 12.19 \\
\hline $\mathbf{d}$ & 1,465 & 8.2 & 68 & 8.48 & 1,533 & 8.21 \\
\hline $\mathbf{e}$ & 990 & 5.54 & 137 & 17.08 & 1,127 & 6.04 \\
\hline $\mathbf{f}$ & 307 & 1.72 & 26 & 3.24 & 333 & 1.78 \\
\hline $\mathbf{g}$ & 286 & 1.6 & 46 & 5.74 & 332 & 1.78 \\
\hline $\mathbf{h}$ & 44 & 0.25 & 1 & 0.12 & 45 & 0.24 \\
\hline $\mathbf{i}$ & 26 & 0.02 & 2 & 0.25 & 28 & 0.15 \\
\hline $\mathbf{j}$ & 8 & 0.04 & 4 & 0.5 & 12 & 0.06 \\
\hline $\mathbf{k}$ & 4 & 0.02 & 1 & 0.12 & 5 & 0.03 \\
\hline Other & 1,427 & 7.99 & 87 & 10.85 & 1,514 & 8.11 \\
\hline Total & 17,861 & 100 & 802 & 100 & 18,663 & 100 \\
\hline
\end{tabular}

Source: (General Directorate of Highways, 2018b)

As seen from traffic accident data (Table 4), the greatest share of traffic accidents caused by pedestrian is the failure to comply with passing rules in places where there are no crossings or intersections. This is particularly common in urban areas. People do not obey these rules in order not to waste time or to use easy options.

The penalty for not complying with the rules must be absolute, especially in vital situations like traffic. The following Figure 2 shows the traffic accidents during the 2016 period. Despite the fact that the traffic accidents caused by pedestrians are too many, the number of traffic fines given only 3286 in whole country. In fact, even this amount of punishment can be one of the reasons for the high number of traffic accidents. Laws do not reduce crimes, but enforcement of laws can cause crimes to diminish. That's why there must be sanctions on the rules. This will reduce the impact of people on traffic accidents and make people more cautious. 


\section{Traffic Penalty}

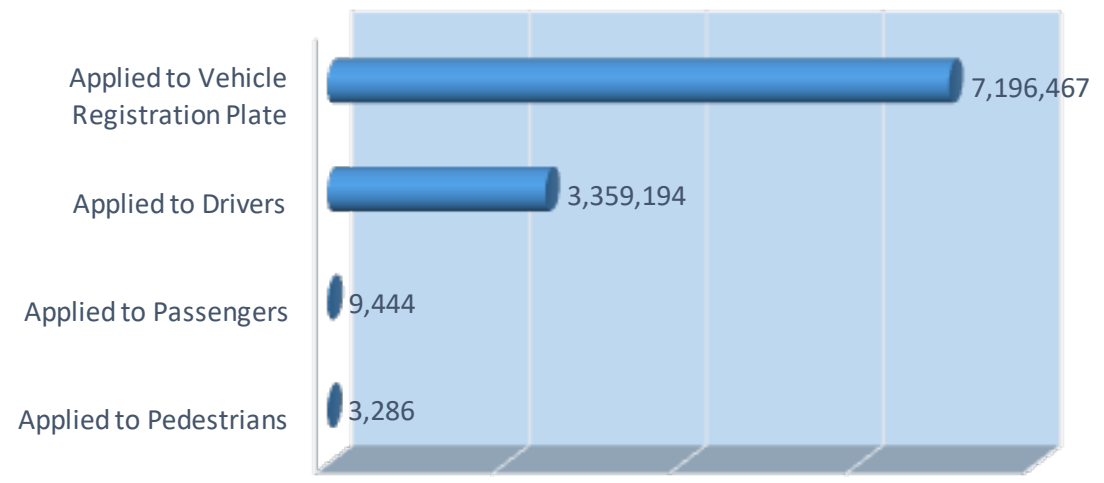

Traffic Penalty

Fig. 2.

Distribution of Implemented Traffic Penalty in 2016

Source: (Turkey National Police, 2018c)

When an evaluation is made for the pedestrian; the underpasses and pedestrian ways made for them must not be seen as time-consuming and exhausting. These measures are taken for pedestrian safety. People will use pedestrians and pedestrians more consciously as long as they have this idea. On the other hand, existing traffic fines for the pedestrians should be applied more. Because traffic penalties will increase the commitment to the rules and reduce traffic accidents.

As a result, pedestrians in traffic accidents in Turkey they have a high defect rate, and this defect is increasing the number of deaths in accidents. Because pedestrians are the unprotected elements of the traffic. Being unprotected can cause a major disaster from small accidents. Drivers should be careful not to make accidents, but pedestrians must be as careful as drivers at least to protect their own safety. Driver mistakes are generally result of financial losses from traffic accidents. However, pedestrian mistakes can cause their own loss of life. As noted in the first part of the study, it is possible to recover material losses but not recover the material losses.

\section{Conclusion}

People need to comply with the rules in order to reduce the number of traffic accidents. Adhering to the rules is about the level of education. Therefore, the government should give importance to this issue and traffic education should be given to people in the primary school. The number of traffic lessons should be increased in schools. The traffic week can be an important opportunity for people to become aware of 
this issue. Practical traffic activities should be organized especially for children.

On the other hand, people should be tolerant of traffic and help each other. There is no doubt that as the number of well trained and educated people increases, the number of traffic accidents will also decrease. If this issue is assessed another point of view, traffic rules can be made universal and measures to be taken against traffic accidents can be improved more easily. In this way; when a pedestrian changes city or country, not exposed to traffic problems. Another important point is that; bridges, intersections and stairs made for the benefit of people should be such as to make life easier. It should not cause people to suffer and not cause excessive loss of time.

\section{References}

Aziz, H.A.; Ukkusuri, S.V.; Hasan, S. 2012. Exploring the determinants of pedestrian-vehicle crash severity in New York City, Accident Analysis Prevention 50: 1298-1309.

Codur, M.Y.; Tortum, A. 2015. An artificial neural network model for highway accident prediction: a case study of Erzurum, Turkey, Promet - Traffice Transportation 27(3): 217-225

General Directorate of Highways. 2018a. Summary of traffic accidents in Turkey. Available from Internet: <http://www.kgm.gov.tr/SiteCollectionDocuments/ KGMdocuments/Trafik/TrafikKazalariOzeti2017.pdf>.

General Directorate of Highways. 2018b. Summary of traffic accidents in Turkey. Available from Internet: <http://www.kgm.gov.tr/SiteCollectionDocuments/ KGMdocuments/Istatistikler/TrafikveUlasimBilgiler i/17TrafikUlasimBilgileri.pdf $>$.

Glász, A.; Juhász, J. 2017. Car-pedestrian and car-cyclist accidents in Hungary, Transportation Research Procedia 24: 474-481.
Gokdag, M.; Atalay, A. 2015. Traffic education and effective on the traffic accidents, Igdir Univesity Institute of Science Journal 8(2): 272-283.

Haleem, K.; Alluri, P.; Gan, A. 2015. Analyzing Pedestrian Crash Injury Severity at Signalized and Non-Signalized Locations, Accident Analysis \& Prevention 81: 14-23.

Kadali, B.R.; Vedagiri, P. 2013. Modelling pedestrian road crossing behavior under mixed traffic condition, European Transport 55(3): 1-17.

Levulytė, L.; Baranyai, D.; Sokolovskij, E.; Török, Á. 2017. Pedestrians' role in road accidents, International Journal for Traffic and Transport Engineering 7(3): 328341.

Onelcin, P.; Alver, Y. 2014. Pedestrian Behaviors at Signalized Intersections in Izmir, Turkey. In Proceedings of the International Conference on Traffic and Transport Engineering - ICTTE2014, Belgrade, Serbia, 801-806.

Ozen, E.; Genc, E.; Kaya, Z. 2014. Awareness of Traffic Accidents and Thoughts on Traffic and Traffic: The Case of Uşak Province, Optimum Journal of Economics and Management Sciences 1(1): 1-19.

Tortum, A.; Çodur, M.Y.; Kılınç, B. 2012. Modeling Traffic Accidents in Turkey Using Regression Analysis, Igdir Univesity Institute of Science Journal 2(3): 69-78.

Turkey National Police. 2018a. Traffic Statistics Bulletin. Available from Internet: <http://www.trafik.gov.tr/ SiteAssets/istatistik/2017s.pdf $>$.

Turkey National Police. 2018b. Traffic Statistics Bulletin. Available from Internet: <http://www.trafik. gov.tr/Sayfalar/Istatistikler.aspx $>$.

Turkey National Police. 2018c. Traffic Statistics Bulletin. Available from Internet: <http://www.trafik.gov.tr/ SiteAssets/istatistik/Arac Surucu.pdf $>$. 
Turkish Statistical Institute. 2018. Traffic Accidents Statistics. Available from Internet: <www.tuik.gov.tr/ ulastirmavehaberlesme>.

Uttley, J.; Fotios, S. 2017. The effect of ambient light condition on road traffic collisions involving pedestrians on pedestrian crossings, Accident Analysis and Prevention 108: 189-200.

World Health Organization. 2004. Preventing road traffic injury: a public health perspective for Europe. Available from Internet: <http://www.euro.who. int/_data/assets/pdf_file/0003/87564/E82659.pdf $>$.
World Health Organization. 2015. Available from Internet: <http://www.who.int/violence_injury_ prevention/road_safety_status/2015/GSRRS2015_ Summary_EN_final2.pdf?ua $=1>$.

Xie, S.; Wang, S.; Lam, W.H.K. 2017. Pedestrian crossing behavior at signalized crosswalks, Journal of Transportation Engineering 139(7): 678-685.

Zebala, J.; Ciępka, P.; Reza, A. 2012. Pedestrian acceleration and speeds, Problems of Forensic Sciences 91: 227-234. 